\title{
Are Demographic Characteristics Associated with Advance Directive Completion? A Secondary Analysis of Two Randomized Trials
}

\author{
Joanna L. Hart, MD MSHP', Nicole B. Gabler, $P h D^{7}$, Elizabeth Cooney, $M P H^{7}$, Brian Bayes, $\mathrm{MS}^{7}$, \\ Kuldeep N. Yadav, BA' , Cindy Bryce, $P h D^{2}$, and Scott D. Halpern, MD PhD ${ }^{7}$
}

'Palliative and Advanced Illness Research Center, University of Pennsylvania, Philadelphia, PA, USA; ${ }^{2}$ Department of Health Policy and Management, Graduate School of Public Health, University of Pittsburgh, Pittsburgh, PA, USA.

KEY WORDS: advance care planning; advance directive; health policy; healthcare disparities.

J Gen Intern Med 33(2):145-7

DOI: $10.1007 / \mathrm{s} 11606-017-4223-7$

(c) Society of General Internal Medicine 2017

\section{INTRODUCTION}

Preferences for future medical treatments may be documented in a legal document known as an advance directive (AD). Despite national efforts to promote AD completion, ${ }^{1}$ men, blacks, and those with less education less frequently complete ADs. ${ }^{2,3}$ However, it remains unclear whether such groups differ in their willingness to complete ADs or have different opportunities to do so. The latter would suggest disparities in access to advance care planning. We sought to elucidate this key distinction by assessing associations between demographic characteristics and $\mathrm{AD}$ completion within two randomized controlled trials (RCTs) that presented uniform opportunities to participants who may be targeted for AD completion.

\section{METHODS AND FINDINGS}

We performed secondary analyses of data from two RCTs (NCT02289105 and NCT02017548). RCT 1 compared three ADs that differed in how information was presented to 484 people with serious illnesses enrolled from 30 clinics within two Pennsylvania health systems between February 2014 and March $2016 .^{4}$ The study protocol for trial 1 has been published

Table 1 Characteristics of Enrolled Participants in Two Randomized Trials Supporting Advance Directive Completion

\begin{tabular}{llll}
\hline \hline Characteristic & Trial 1 & & Trial 2 \\
\cline { 2 - 2 } $\begin{array}{l}\text { Seriously ill } \\
\text { patients }\end{array}$ & & $\begin{array}{l}\text { New health system } \\
\text { employees }\end{array}$ \\
\hline $\begin{array}{l}\text { Number enrolled } \\
\begin{array}{l}\text { Age in years (median, } \\
\text { interquartile range) }\end{array}\end{array}$ & $\begin{array}{l}484(56.0-69.5) \\
\begin{array}{l}\text { Sex } \\
\quad \text { Female }\end{array}\end{array}$ & $\begin{array}{l}1279 \\
\text { Male }\end{array}$ & $212(25.0-38.0)$ \\
\hline & $270(56.0 \%)$ & $333(26.0 \%)$ \\
\hline
\end{tabular}

Published online November 20, 2017
Table 1. (continued)

\begin{tabular}{|c|c|c|}
\hline \multirow[t]{2}{*}{ Characteristic } & \multirow{2}{*}{$\begin{array}{l}\text { Trial } 1 \\
\begin{array}{l}\text { Seriously ill } \\
\text { patients }\end{array}\end{array}$} & \multirow{2}{*}{$\begin{array}{l}\text { Trial } 2 \\
\begin{array}{l}\text { New health system } \\
\text { employees }\end{array}\end{array}$} \\
\hline & & \\
\hline $\begin{array}{l}\text { Other/prefer not to } \\
\text { answer }\end{array}$ & - & $28(2.2 \%)$ \\
\hline \multicolumn{3}{|l|}{ Race } \\
\hline White & $337(69.6 \%)$ & $678(53.0 \%)$ \\
\hline Black & $123(25.4 \%)$ & $344(26.9 \%)$ \\
\hline Mixed or Other & $24(5.0 \%)$ & $197(15.4 \%)$ \\
\hline Prefer not to answer & - & $60(4.7 \%)$ \\
\hline \multicolumn{3}{|c|}{ Highest level of education completed } \\
\hline High school or less & $172(35.5 \%)$ & $108(8.4 \%)$ \\
\hline Some college & $111(23.2 \%)$ & $269(21.0 \%)$ \\
\hline College degree & $116(24.3 \%)$ & $602(47.1 \%)$ \\
\hline Post-college degree & $79(16.5 \%)$ & $224(17.5 \%)$ \\
\hline Missing & - & $76(5.9 \%)$ \\
\hline \multicolumn{3}{|l|}{ Religious affiliation } \\
\hline Catholic & $165(34.1 \%)$ & Not asked \\
\hline Protestant & $173(35.7 \%)$ & \\
\hline Other Christian & $48(9.9 \%)$ & \\
\hline Other & $98(20.3 \%)$ & \\
\hline \multicolumn{3}{|l|}{ Marital status } \\
\hline Currently married & $309(64.4 \%)$ & Not asked \\
\hline Never married & $68(14.2 \%)$ & \\
\hline Divorced & $60(12.5 \%)$ & \\
\hline Separated & $13(2.7 \%)$ & \\
\hline Widowed & $30(6.3 \%)$ & \\
\hline \multicolumn{3}{|l|}{ Household income (annual) } \\
\hline Less than $\$ 30,000$ & $129(26.7 \%)$ & Not asked \\
\hline$\$ 30,000-59,999$ & $135(27.9 \%)$ & \\
\hline$\$ 60,000-89,999$ & $92(19.0 \%)$ & \\
\hline$\$ 90,000$ or more & $128(26.5 \%)$ & \\
\hline \multicolumn{3}{|l|}{ Primary diagnosis } \\
\hline Chronic obstructive & $23(4.8 \%)$ & Not applicable \\
\hline pulmonary disease & & \\
\hline Other incurable lung & $21(4.3 \%)$ & \\
\hline \multicolumn{3}{|l|}{ disease } \\
\hline Gastrointestinal cancer & $99(20.5 \%)$ & \\
\hline Genitourinary cancer & $90(18.6 \%)$ & \\
\hline Breast cancer & $29(6.0 \%)$ & \\
\hline $\begin{array}{l}\text { Pancreatic or gallbladder } \\
\text { cancer }\end{array}$ & $59(12.2 \%)$ & \\
\hline End-stage renal disease & $35(7.2 \%)$ & \\
\hline Heart failure & $11(2.3 \%)$ & \\
\hline \multirow{2}{*}{\multicolumn{3}{|c|}{ sclerosis }} \\
\hline & & \\
\hline Prior clinical degree* & Not asked & $269(21.0 \%)$ \\
\hline \multicolumn{3}{|l|}{ Type of employment } \\
\hline Full-time & Not applicable & $933(73.0 \%)$ \\
\hline Part-time & & $346(27.1 \%)$ \\
\hline
\end{tabular}

*Participants were considered to have clinical degrees if they had any of the following designations: $M D, M S N, B S N, R N, L P N, D O, N P, P A$, DPT, PharmD, DVM, CRNA, speech pathology, CNA, CMA, surgical tech, medical assistant, nurse assistant, or medical technologist 


\section{A Seriously ill patients}

\begin{tabular}{|c|c|c|c|}
\hline \multicolumn{2}{|l|}{ Characteristic } & OR $[95 \% \mathrm{Cl}]$ & p-value \\
\hline \\
\hline$\leq 49$ & $\longmapsto \quad \vdots$ & $0.62[0.32,1.23]$ & 0.17 \\
\hline $50-59$ & $\longmapsto$ & $1.04[0.62,1.76]$ & 0.87 \\
\hline $60-69$ & & -- & -- \\
\hline$\geq 70$ & $\longmapsto \quad \vdots$ & $0.67[0.39,1.14]$ & 0.14 \\
\hline \multicolumn{4}{|l|}{ Sex } \\
\hline Female & & --- & --- \\
\hline Male & - & $1.08[0.70,1.67]$ & 0.72 \\
\hline \multicolumn{4}{|l|}{ Race } \\
\hline \multicolumn{4}{|l|}{ White } \\
\hline Black & $\longmapsto$ & $0.77[0.42,1.41]$ & 0.4 \\
\hline Other & 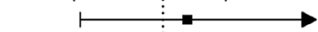 & $1.16[0.46,2.88]$ & 0.76 \\
\hline \multicolumn{4}{|l|}{ Marital Status } \\
\hline Married & & --- & --- \\
\hline Never married & $\Rightarrow \vdots$ & $0.90[0.46,1.79]$ & 0.77 \\
\hline Divorced & $\longmapsto-\vdots$ & $0.71[0.36,1.39]$ & 0.31 \\
\hline Separated & $\longrightarrow$ & $0.78[0.19,3.22]$ & 0.74 \\
\hline Widowed & $\longmapsto$ & $1.18[0.48,2.92]$ & 0.72 \\
\hline \multicolumn{4}{|l|}{ Highest level of education completed } \\
\hline Less than high school & & $1.10[0.43,2.86]$ & 0.84 \\
\hline High school diploma & & -- & -- \\
\hline Some college & $\vdash$ & $1.42[0.79,2.53]$ & 0.24 \\
\hline College degree & $\longmapsto$ & $0.97[0.54,1.77]$ & 0.93 \\
\hline Post-college degree & $\longmapsto$ & $0.94[0.48,1.86]$ & 0.87 \\
\hline \multicolumn{4}{|l|}{ Income } \\
\hline$<\$ 30,000$ & $\mapsto$ & $1.31[0.69,2.48]$ & 0.41 \\
\hline$\$ 30,000-\$ 59,999$ & & -- & --- \\
\hline$\$ 60,000-\$ 89,999$ & - & $1.27[0.68,2.41]$ & 0.45 \\
\hline$\geq \$ 90,000$ & $\longmapsto$ & $0.80[0.44,1.47]$ & 0.48 \\
\hline \multicolumn{4}{|l|}{ Religious affiliation } \\
\hline Protestant & & --- & --- \\
\hline Catholic & $\mapsto$ & $1.51[0.88,2.60]$ & 0.14 \\
\hline Other, Christian & 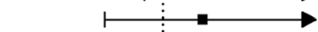 & $1.26[0.62,2.57]$ & 0.52 \\
\hline Other, non-Christian & 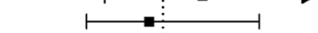 & $0.91[0.50,1.63]$ & 0.74 \\
\hline \multicolumn{4}{|l|}{ Primary diagnosis } \\
\hline Gastrointestinal cancer & & -- & --- \\
\hline Chronic obstructive pulmonary disease & $=$ & $0.67[0.24,1.86]$ & 0.44 \\
\hline Incurable lung disease, non-COPD & ⺊ & $2.54[0.76,8.56]$ & 0.13 \\
\hline Heart failure & $\rightarrow$ & $1.22[0.27,5.60]$ & 0.8 \\
\hline End-stage renal disease & $\rightarrow$ & $0.88[0.36,2.16]$ & 0.78 \\
\hline Amyotrophic lateral sclerosis & $\vdots$ & $1.32[0.50,3.48]$ & 0.57 \\
\hline Breast cancer & $\longmapsto \quad \vdots$ & $0.58[0.22,1.57]$ & 0.29 \\
\hline Genitourinary cancer & 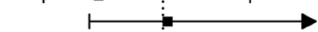 & $1.03[0.52,2.02]$ & 0.93 \\
\hline Lung cancer & $\longmapsto-\vdots$ & $0.64[0.33,1.27]$ & 0.2 \\
\hline \multirow[t]{5}{*}{ Pancreatic or gallbladder cancer } & $\longmapsto \vdots$ & $0.89[0.44,1.81]$ & 0.74 \\
\hline & $T$ & & \\
\hline & 0.5 & & \\
\hline & $\begin{array}{c}{\stackrel{\text { Lower AD }}{ }} \stackrel{\text { Higher AD }}{\text { Completion Rate }}\end{array}$
\end{tabular}$} &{ } &{ } \\
{\hline} &{\text { Odds Ratio }} &{ } &{ } \\
$\hline$\end{array}$

\section{B Health system employees}

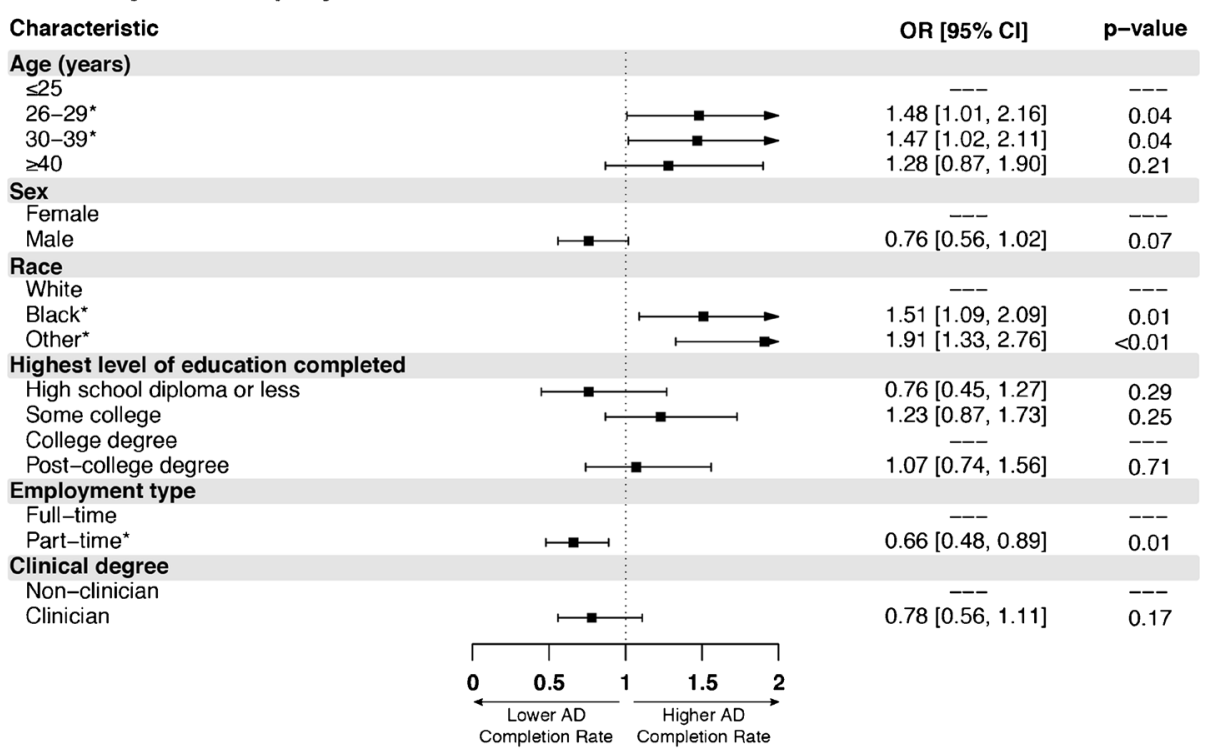

Odds Ratio

Figure 1 Characteristics of participants as predictors of advance directive completion. $\mathbf{C I}=$ confidence interval. Characteristics entered in fully adjusted logistic regression with randomization arm (and recruiter for RCT 1) entered as fixed effect. 
elsewhere. ${ }^{4}$ RCT 2 compared methods of encouraging AD completion among new employees at a Pennsylvania healthcare system between November 2014 and August 2015. An AD completion module was inserted into the online system through which all new healthcare system employees complete employment documents. Employees were randomly assigned a module that either did or did not require them to make an active choice of whether to complete an AD.

Participants in each trial received standardized educational materials and a professionally endorsed $\mathrm{AD}$ form on which they could indicate preferences for five life-sustaining interventions and a general treatment goal. Institutional review boards approved all procedures.

The primary outcome in these secondary analyses was $\mathrm{AD}$ completion, defined as patients returning an $\mathrm{AD}$ via mail in RCT 1 and employees completing an AD online in RCT 2. Independent variables were all demographics measured in each trial (Table 1). Each trial was independently analyzed.

We used multivariable logistic regression to examine associations between demographics and AD completion. Randomization arm was entered as a fixed effect in analyses of both RCTs, and recruiter was an additional fixed effect for RCT 1 .

\section{RESULTS}

Characteristics of participants in each RCT are reported in Table 1. In RCT 1, 286 of 484 seriously ill outpatients (59.1\%) completed an $\mathrm{AD}$. In multivariable analyses, none of the measured patient characteristics (age, sex, race, marital status, income, level of education, religious affiliation, and primary diagnosis) were associated with $\mathrm{AD}$ completion (all $p>0.10$; Fig. 1a).

In RCT 2, 355 of the 1279 participating employees (27.8\%) completed an $\mathrm{AD}$. In fully adjusted models, participants who were black $(\mathrm{OR}=1.51 ; 95 \% \mathrm{CI}=1.09-2.09)$ or of mixed $/$ other race $(\mathrm{OR}=1.91 ; 95 \% \mathrm{CI}=1.33-2.76)$ were significantly more likely than white participants to complete an $\mathrm{AD}$ (Fig. 1b). Part-time employees were less likely than full-time employees to complete ADs (OR $=0.66 ; 95 \% \mathrm{CI}=0.48$ $0.89)$. No other characteristic was significantly associated with AD completion (all $p>0.05$ ).

\section{DISCUSSION}

This study shows that when all individuals are given the same opportunities to complete ADs, demographic characteristics are not consistently associated with AD completion. Because results from previous observational studies - which found that men, blacks, and less-educated persons completed ADs less frequently-were not observed when equal opportunities to complete ADs were ensured, those prior studies were likely identifying disparities in patients' access to such opportunities rather than differences in patients' willingness to complete ADs.

The findings of this study may not generalize beyond the populations studied. RCT 1 participants agreed to participate in a study of ADs, perhaps creating a motivated cohort. The employees in RCT 2 were younger and may approach ADs differently from the general public. However, both patients and healthy individuals have been targeted for AD efforts. We cannot draw conclusions about unmeasured participant characteristics. Finally, we cannot rule out the possibility that the lack of observed associations stemmed from insufficient power, but the point estimates of most of the effects argue against this possibility.

Our findings suggest that future work should seek to mitigate system- or clinician-based barriers to offering opportunities for $\mathrm{AD}$ completion equally, rather than focusing solely on different demographic groups' preferences for completing ADs. By providing equal opportunities for $\mathrm{AD}$ completion to all patients, such efforts may also reduce demographic differences in the intensity of end-of-life care that patients receive. $^{5}$

Acknowledgements: We would like to thank Michael Olorunnisola, Lucy Chen, Sarah Grundy, Stephanie Szymanski, Margaret W. Hays, Heather Tomko, and Michael Josephs for their contributions to these clinical trials. This work has been directly supported by the Otto Haas Charitable Trust and the Gordon and Betty Moore Foundation. Dr. Hart was supported by grant K12HL109009 from the National Heart, Lung, and Blood Institute, National Institutes of Health. A previous version of this work was presented orally by Dr. Hart at the American Thoracic Society International Conference in 2017.

Corresponding Author: Joanna L. Hart, MD MSHP; palliative and Advanced Illness Research Center University of Pennsylvania, Philadelphia, PA, USA. (e-mail: joanna.hart@uphs.upenn.edu).

\section{Compliance with Ethical Standards:}

Conflict of Interest: The authors declare that they do not have a conflict of interest.

\section{REFERENCES}

1. Halpern SD. Toward evidence-based end-of-life care. N Engl J Med 2015;373(21):2001-3. https://doi.org/10.1056/NEJMp1509664.

2. Huang IA, Neuhaus JM, Chiong W. Racial and ethnic differences in advance directive possession: role of demographic factors, religious affiliation, and personal health values in a national survey of older adults. J Palliat Med. 2016;19(2):149-56. https://doi.org/10.1089/jpm.2015. 0326.

3. Harrison KL, Adrion ER, Ritchie CS, Sudore RL, Smith AK. Low completion and disparities in advance care planning activities among older medicare beneficiaries. JAMA Intern Med. 2016;176(12):1872-5. https:// doi.org/10.1001/jamainternmed.2016.6751.

4. Gabler NB, Cooney E, Small DS, Troxel AB, Arnold RM, White DB, et al. Default options in advance directives: study protocol for a randomised clinical trial. BMJ Open. 2016;6(6):e010628. https://doi.org/10.1136/ bmjopen-2015-010628.

5. Kelley AS, Ettner SL, Morrison RS, Du Q, Wenger NS, Sarkisian CA. Determinants of medical expenditures in the last 6 months of life. Ann Intern Med. 2011;154(4):235-42. https://doi.org/10.7326/0003-4819154-4-201102150-00004 